\title{
BRANQUITUDE E REPRESENTAÇÕES SOBRE IMIGRANTES HAITIANOS NO OESTE CATARINENSE
}

\author{
Claudete Gomes Soares ${ }^{1}$ \\ Neuri José Andreola ${ }^{2}$
}

RESUMO: Este artigo tem como objetivo apresentar e discutir princípios e ideias norteadoras de uma pesquisa em andamento sobre os significados atribuídos à presença haitiana no oeste catarinense cuja constituição local está fortemente associada à identidade branca, marcadamente italiana e alemã, em prejuízo de outras identidades: caboclos e povos indígenas. O objetivo é evidenciar como essa branquitude hegemônica tem sido acionada nas relações entre moradores locais e imigrantes haitianos. Como forma de organizar os caminhos da pesquisa, revisitamos as categorias "preconceito de marca" e "preconceito de origem" cunhadas por Oracy Nogueira e acionamos as categorias de "estabelecidos" e "outsiders" de Elias e Scotson (2000). O trabalho de campo tem mostrado um processo de estereotipagem racial (STUART HALL, 2016) dos imigrantes haitianos pelos moradores brasileiros, fundamentado na suposta superioridade da origem europeia.

PALAVRAS-CHAVE: Relações Raciais; Imigração; Haiti; Santa Catarina.

\section{WHITENESS AND REPRESENTATIONS ON HAITIAN IMMIGRANTS IN THE WEST OF SANTA CATARINA}

\footnotetext{
${ }^{1}$ É doutora em Sociologia pela Universidade Estadual de Campinas, professora do curso de Ciências Sociais da Universidade Federal da Fronteira Sul e coordenadora do NEABI- UFFSCH. É líder do grupo de pesquisa Cultura Política e Diversidade, atuando na linha de pesquisa Política, Gênero e Identidade. E-mail: claudete.soares@uffs.edu.br

${ }^{2}$ Graduado em Ciências Sociais pela Universidade Federal da Fronteira Sul - Campus Chapecó. E-mail: neandreola@yahoo.com.br. Autor da monografia de trabalho de conclusão de curso "Brasileiros e estrangeiros: as relações de sociabilidade entre o grupo de brancos e o grupo de negros em um bairro em Chapecó”.
} 


\begin{abstract}
This paper aims at presenting and discussing guiding principles and ideas of an ongoing research regarding the meanings assigned to Haitian presence in the west area of Santa Catarina, which local constitution is strongly associated to Caucasian identity, specially Italian and German over other identities: "caboclos" and indigenous groups. The goal is to make evident how this hegemonic whiteness have been trigged in the social relations between local habitants and Haitian immigrants. As a mean for organizing the research path, we have revisited "mark prejudice" and "origin prejudice" categories, named by Oracy Nogueira, and we have used Elias e Scotson (2000) "established" and "outsiders" categories. The fieldwork has been showing a process of racial stereotyping (STUART HALL, 2016) of Haitian immigrants by Brazilian residents, built on the supposed superiority of the European origin.
\end{abstract}

KEYWORDS: Racial Relations; Immigration; Haiti; Santa Catarina.

\title{
INTRODUÇÃO
}

Esse artigo é resultado de um esforço de interpretação dos significados atribuídos à presença haitiana no oeste catarinense. ${ }^{3} \mathrm{~A}$ presença de imigrantes haitianos em uma região do Brasil hegemonicamente branca trouxe como desafio a compreensão da relação de interdependência entre o grupo de trabalhadores estrangeiros, negros, com o grupo de brasileiros, de maioria branca, a partir da ideia de interdependência entre grupos, explorada por Norbert Elias e John Scotson no livro "Estabelecidos e Outsiders" (2000). Esse processo de interdependência grupal local tem sido marcado por representações e discursos construídos a partir da diferença racial, repertoriados no processo colonial brasileiro, na história do estado de Santa Catarina e do oeste catarinense como territórios com poucas ligações com a experiência da escravidão no Brasil.

Apesar de a região oeste catarinense contar também com a presença de senegaleses que poderiam fazer parte dessa análise, nossas

\footnotetext{
${ }^{3}$ Os dados e as discussões apresentados nesse artigo são parte dos resultados parciais do projeto "Negritude e Branquidade: uma análise da integração haitiana no Oeste Catarinense" com apoio financeiro da FAPESC - Fundação de Amparo à pesquisa e inovação do estado de Santa Catarina - Edital de chamada pública FAPESC nº 07/2015. A pesquisa conta com a colaboração das bolsistas Taíse Staudt e Vivian Stefany Ribeiro. A pesquisa também conta com a participação da estudante Eliziane Tamanho Oliverira que desenvolveu um trabalho de monografia sobre a relação entre estudantes haitianos e brasileiros no contexto da Universidade Federal da Fronteira Sul, no compus Chapecó.
}

Temáticas, Campinas, 25, (49/50): 85-114, fev/dez. 2017 
considerações nesse artigo terão como foco a integração haitiana, em razão desse grupo de imigrante estrangeiro estar no contexto local desde 2011 e ser em número maior do que os imigrantes senegaleses. Pesquisas futuras poderão abarcar os imigrantes senegaleses, imersos no mesmo processo de interdependência grupal. A escolha dos haitianos como ponto de partida da pesquisa foi uma consequência do fato de eles serem em maior número na cidade e contarem com maiores recursos institucionais para a sua integração. É importante ressaltar os desdobramentos da presença do Brasil no Haiti, por meio da Missão das Nações Unidas para Estabilizar o Haiti (MINUSTAH) e acordos firmados, depois do terremoto de 2010, que preveem a regularização da situação de trabalhadores e estudantes haitianos no Brasil.

Em um primeiro momento, a entrada dos imigrantes haitianos em solo brasileiro foi respaldada pelo Estatuto dos Refugiados (Lei 9.474 de 22 de julho de 1997). A partir de 2012, um novo marco legal foi constituído especificamente para normatizar a entrada de imigrantes haitianos no Brasil, trata-se da Instrução Normativa 97/2012, aprovada pelo Conselho Nacional de Imigração, que resolve atribuir um caráter diferenciado ao nacional do Haiti, concedendo-lhe o visto humanitário (Resolução Normativa CNIg no 97 de 12/01/2012).

Nesse artigo pretendemos apresentar e discutir alguns elementos que têm norteado a pesquisa em andamento que tem como objetivo desvendar as relações de poder, status e prestígio, presentes nos processos de interdependência entre os grupos locais e estrangeiros. A integração desses imigrantes no mercado de trabalho (frigoríficos, construção civil, comércio local), na educação - por meio do Programa Pro-HaitiUFFS, que criou uma política de vagas suplementares para haitiano na Universidade Federal da Fronteira Sul (UNIVERSIDADE FEDERAL DA FRONTEIRA SUL, 2013) - e nas formas de sociabilidade cotidianas tem sido analisada tendo em consideração as relações de interdependência entre brancos e não-brancos no marco de um regime racializado de representação, produtor de estereótipos (HALL, 2016). A pesquisa tem se desenvolvido por meio de observação participante, entrevistas, grupos de discussão, conversas informais, levantamento de dados na imprensa 
local. Com o uso desses recursos, da pesquisa qualitativa, procura-se verificar como as relações e representações mediadas por categorias raciais e étnicas, construídas em um processo de longa duração (ELIAS, 1994), são acionadas, revisitadas, atualizadas, na interdependência de haitianos e a população local, nesse curto período de presença haitiana na região oeste catarinense.

O mito fundador do oeste catarinense tem como protagonista o imigrante europeu de origem europeia, imaginário que encontra correspondência nos dados censitários do IBGE. De acordo com os dados do perfil de cor do censo do IBGE de 2010 para a cidade de Chapecó: $76,6 \%$ da população é branca; $19,2 \%$ parda; $2,6 \%$ preta; $0,7 \%$, indígena e $0,5 \%$ amarela.

Com um contraponto a essa realidade, os imigrantes do presente têm a negritude de seus corpos como marcadores da diferença. É forçoso indagar de que forma esse corpo negro é significado em um contexto formado majoritariamente por brancos e constituído por meio da hegemonia da branquitude 4 , caracterizada pela atribuição de maior valor social e prestígio ao grupo branco e pela associação desse grupo ao progresso, trabalho, desenvolvimento e civilização. É possível encontrar na figuração específica das relações entre os moradores locais e estrangeiros haitianos em Chapecó e região atualizações das relações de poder entre brancos e não-brancos construídas no marco histórico da colonização e da escravidão moderna e do racismo estrutural que organiza lugares de brancos e não brancos na sociedade brasileira, com toques de particularidades regionais.

Diante dessa problemática, uma questão que se coloca é a do lugar do estado de Santa Catarina na construção das representações e discursos marcados pela diferença racial no contexto da sociedade brasileira. A representação dominante sobre a formação social do estado catarinense

\footnotetext{
${ }^{4}$ Nesse texto estamos usando os termos branquitude e branquidade como sinônimos, ambos fazem referência ao lugar de poder e privilégio associados ao fenótipo branco, euroreferenciado. Estudos têm utilizado o termo com o mesmo significado. Os exemplos são: o livro organizado por Vron Ware (2004), cujo título na tradução brasileira é "Branquidade: identidade branca e multiculturalismo", e o trabalho de Maria Aparecida Bento (2014), que têm utilizado o termo branquidade; enquanto Lia Vainer Schucman (2013) tem utilizado o termo branquitude.
}

Temáticas, Campinas, 25, (49/50): 85-114, fev/dez. 2017 
coloca-o fora da narrativa que caracteriza o Brasil como mestiço e associado à cultura ibérica. O estado de Santa Catarina teria se constituído a partir do seu distanciamento do centro da economia colonial e nele, portanto, a presença africana e negra e as relações de poder mediadas pela racialização de povos seriam mínimas ou não seriam significativas.

As entrevistas utilizadas nesse artigo foram realizadas pelo graduado em Ciências Sociais (UFFS) Neuri José Andreola, no segundo semestre de 2015, durante a realização de seu Trabalho de Conclusão de Curso intitulado Brasileiros e estrangeiros: as relaçöes de sociabilidade entre o grupo de brancos e o grupo de negros em um bairro em Chapecó. Os nomes utilizados para identificar os entrevistados são fictícios.

\section{BRANQUITUDE E PRESENÇA NEGRA NO ESTADO DE SANTA CATARINA}

É importante sinalizar que um país da dimensão territorial do Brasil experimentou e experimenta diferentes configurações demográficas que foram condicionadas pelos fluxos econômicos, intensidade da presença do trabalho escravo, ocupação do território e a permanência ou extermínio das populações originárias.

O estado de Santa Catarina é o estado brasileiro com maior percentual de população identificada como branca, $84 \%$ de sua população, segundo dados do censo do IBGE de 2010. Segundo Ilka Boaventura Leite (1996, p.39), isso faz com que ele e a região sul, de maneira mais ampla, sejam vistos como uma "Europa incrustada no Brasil" e como "lócus do projeto imigrantista implantado desde meados do século XIX".

É preciso lembrar que entre o final do século XIX e começo do século XX o projeto desenhado pelas elites e pelo estado brasileiro para o Brasil era o do branqueamento da nação, por meio do incentivo à imigração europeia, especialmente, alemã e italiana. Schwarcz (1995) mostra como as oscilações a que esteve submetida a identidade nacional brasileira giraram em torno de uma mestiçagem particular, que de racial e detratora, se fez moral e nacional. 
A primeira apropriação da particularidade racial como definidora de Brasil se deu sob a influência das teorias científicas raciais do século XIX. Alguns pensadores, autorizados pela legitimidade científica, passaram a defender a ideia de diferenças entre as pessoas, enfatizando a existência de raças diversas. Essa discussão influenciou a interpretação do Brasil no que tangia as expectativas de sucesso e fracasso da jovem nação. $\mathrm{Na}$ lógica do determinismo racial, que substituíra a ideia de indivíduos iguais, presente no liberalismo clássico, pela de grupo, os indivíduos passaram a ser entendidos e julgados pelos traços físicos e morais de sua raça de origem.

O ideal de uma nação branca levou as elites a rechaçarem tudo o que pudesse lembrar a presença negra na definição do que era o Brasil e a criar a expectativa de que em razão da diminuição da entrada de africanos, com fim da escravidão, e com o incentivo do Estado à presença europeia, a transformação do Brasil em uma nação branca era uma questão de tempo:

\begin{abstract}
A defesa do branqueamento foi unânime, porém diversificada na sua fundamentação. Passou por diversos argumentos, mas principalmente pela crença de que seu sucesso iria ser conseguido pela via do Sul, quer pela presença irrelevante de negros, que pela expectativa de intensa mestiçagem entre "europeus brancos imigrantes" (LEITE, 1996, p.39).
\end{abstract}

Na década de 1930, as representações sobre as diferenças raciais são reconfiguradas em um novo projeto de identidade nacional pautado nas raízes brasileiras, o que levou à incorporação do negro no nacional. Ele deixa de ser "o problema brasileiro" para ser aquilo que particulariza a nação, que lhe confere elementos de identificação, não mais como negro, mas como mestiço. Os referenciais biológicos, até então utilizados para se pensar as relações raciais, são minimizados e substituídos por argumentos de ordem econômica e cultural (SCHWARCZ, 1995). É nesse contexto que se define a política racial brasileira: sustentada ideologicamente pelo mito da democracia racial, sistematizado por Freyre (1995) e legitimado pelo Estado; fundamentada em uma visão romantizada sobre as relações sociais no período da escravidão e nas especificidades da cultura ibérica 
no contato com outros povos. O mito de fundação do Brasil, como o encontro das três raças (ORTIZ, 1985), teve como consequência, para a população negra e indígena, o silenciamento sobre as permanências e atualizações das relações de poder com base na diferença racial.

Apesar do novo projeto de identidade nacional ter como base a incorporação simbólica dos elementos culturais associados à herança africana, a política de Estado de Vargas mantinha-se alinhada ao o projeto de branqueamento. É o que nos mostra Fábio Koifman (2012) em sua análise sobre o serviço de vistos do Ministério da Justiça e Negócios Interiores, no período de 1941-1945, caracterizado por ele como um nacionalismo de caráter xenófobo do Estado Novo. A tese de Koifman é a de que Vargas interferiu direta e impositivamente na política de imigração de forma a restringir grupos que não se encaixassem em seu projeto nacionalista. Segundo o autor, a matriz étnica, cultural e religiosa dos brasileiros defendida por Vargas era a portuguesa, o que teve como consequência uma política de imigração livre para todos os portugueses, considerados imigrantes desejáveis e um fechamento de portas para outros povos europeus, em razão das ameaças políticas que podiam significar para o Estado Novo. Além do motivo político, acreditava-se ainda que os portugueses se casavam mais com os não-brancos, favorecendo, portanto, o projeto do Brasil mestiço. Segundo Koifman, "os judeus eram considerados 'inassimiláveis' e 'infusíveis’, pois dessa maneira eram classificados como indesejáveis” (KOIFMAN, 2012, posição 529, kindle). Além dos judeus, na lista dos indesejáveis estavam os orientais, negros, indígenas e todos os considerados não brancos, bem como pessoas com deficiência e homens e mulheres fora da idade produtiva.

É por meio desses dois contextos - o projeto deliberado de branqueamento do Brasil e do projeto de mestiçagem, fundamentado na cultura ibérica, que devemos procurar entender o discurso hegemônico sobre o estado de Santa Catarina como a "Europa encrustada no Brasil", fundamentado na assertiva de uma relação distanciada desse estado com a escravidão e, portanto, com a herança africana. O dinamismo econômico do estado tem sido frequentemente associado à presença de colônias de imigrantes europeus: alemães e italianos e poloneses, depois 
de 1850. Contudo, um movimento recente na historiografia brasileira vem mostrando o caráter ideológico e marcado racialmente dessa representação, que tem como consequência negar a presença negra no estado.

É essa a orientação que encontramos nos trabalhos de Beatriz Mamigonian (2006), Paulino Cardoso (2007) e Ilka Boaventura Leite (1996). Ao se referir à história de Florianópolis, Mamigonian contesta essa representação. Segundo ela, se é verdade que a economia da Ilha e do Litoral não estavam fundadas na produção para o mercado externo, por meio dos latifúndios, muito das atividades econômicas da Ilha dependiam do trabalho escravo: "não podem ser vistas com desprezíveis as atividades econômicas que se sustentavam sobre a escravização de algo entre um quarto e um terço da população na primeira metade do século XIX" (MAMIGONIAN, 2006, p.5). A autora destaca uma significativa presença de africanos escravizados em torno do estabelecimento de armações baleeiras, as "grandes unidades escravistas no litoral catarinense". Também Ilka Leite enfatiza a invisibilidade do negro em Santa Catarina como resultado de um olhar colonialista que minimizou a presença de africanos ao tomar a economia voltada para o mercado externo como modelo.

Assiste-se, portanto, desde o século XIX, tanto nas práticas como nas representações ao branqueamento do Sul. Além de ser forçada pela historiografia, a população descendente de africanos vai se tornando proporcionalmente menor no quadro do crescimento cada vez maior dos descendentes europeus - confirmando, portanto, o sucesso da política imigratória e da ideologia racista (LEITE, 1996, p.42).

A recuperação dessa percepção hegemônica sobre o desenvolvimento do estado de Santa Catarina é um importante elemento da análise na integração dos haitianos na região oeste catarinense, pois transforma a presença haitiana em um contrapondo negro à hegemonia branca.

A vinda de haitianos para o Brasil é resultado de uma série de fatores relacionados à experiência do Haiti como colônia francesa e ao seu processo de independência marcado por conflitos intensos e às sanções econômicas dele derivadas; às intervenções dos Estados Unidos 
no país; e às experiências políticas internas marcadas por golpes de estado e governos ditatoriais. Além das catástrofes naturais, que têm atingido o país. De acordo com Magalhães e Baeninger (2016), 1.134.000 haitianos vivem foram do Haiti, o que corresponde a $11,05 \%$ da população haitiana. A tese dos autores é a de que esse fluxo migratório intenso se explica pela dependência de muitas famílias que vivem no Haiti das remessas de recursos dos haitianos que estão fora do país. O que os autores denominam de "dependência de remessas". Em sua tese de doutorado, Magalhães (2017, p.197) aponta que o estado de Santa Catarina era em 2014 "o estado que possuía o maior volume de imigrantes haitianos como também o estado que mais admitiu trabalhadores desta nacionalidade".

\section{RACIALIZAÇÃO E IMIGRAÇÃO NO OESTE CATARINENSE}

A cidade de Chapecó, principal cidade da região oeste catarinense, é considerada um polo agroindustrial no seguimento de abate de aves e suínos, contava em 2010 com 183.530 habitantes, segundo dados do último censo do IBGE. A população estimada para 2015, pelo mesmo órgão, era de 205.795. O que mostra um provável crescimento populacional de mais de 20.000 habitantes nos últimos cinco anos. Esse crescimento populacional relaciona-se às potencialidades de desenvolvimento econômico associadas à cidade. Por ocasião do $97^{\circ}$ aniversário de Chapecó, em 2014, o portal de notícias da Globo, o G1 - Santa Catarina, ressalta: "Aos 97 anos, Chapecó se destaca por ofertas de emprego e crescimento". O enfoque da matéria é o crescimento econômico promissor e a abundante oferta de trabalho:

O mercado em Chapecó tem dificuldades para encontrar profissionais que trabalhem fora do horário convencional e nos fins de semana. Só o setor de construção civil tem 450 vagas de emprego para serem preenchidas. Conseguir mão de obra para os frigoríficos tem sido um desafio. Uma das empresas do ramo, por exemplo, tem 5,3 mil funcionários. Desses, 1,4 vieram de outros lugares, até mesmo fora do país. Há trabalhadores de Senegal e Haiti na agroindústria. Eles vêm 
em grupos em busca de uma vida melhor e geralmente ganham oportunidade na indústria (grifos nossos).

É em razão desse contexto que os imigrantes haitianos, que estavam chegando ao Brasil, foram sendo atraídos para o oeste catarinense e absorvidos como força de trabalho, principalmente pela agroindústria de Chapecó, Xaxim e Nova Erechim, para atuar em áreas de trabalhos muitas vezes indesejadas pelos trabalhadores locais. De acordo com dados levantados por Felipe Aires Magalhães (2017), a cidade de Chapecó é a cidade que mais incluiu haitianos no mercado formal de trabalho, à frente de algumas das principais capitais do Brasil que têm recebido imigrantes haitianos. Durante o seu trabalho de campo em Balneário Camboriú, o pesquisador presenciou reuniões de recrutamento nas quais recrutadores de Chapecó faziam promessas sobre salário, condições de trabalho e alojamento, com o intuito de fazer com que os imigrantes haitianos se deslocassem para aquela cidade. O movimento migratório dos haitianos para o Brasil é, inicialmente, caracterizado pela presença masculina, com reduzida presença de mulheres. Outro dado relevante diz respeito ao perfil etário da migração haitiana para o Brasil. "Em relação à idade, mas de $30 \%$ destes imigrantes [dados nacionais] estão concentrados na faixa etária de 25 a 29 anos, seguida daqueles no grupo etário de 30 a 34 anos ... " (FERNANDES \& CASTRO, 2014, p.55). Os dados indicam que a maioria dessa população se encontra na fase mais produtiva e reprodutiva da vida, além do que, segundo registros do Ministério das Relações Exteriores, $80 \%$ dos imigrantes haitianos que solicitaram visto nas representações consulares brasileiras se declaram solteiros (MAGALHÃES, 2017). Certamente esses dados: uma população negra, jovem, masculina, solteira, em fase produtiva e reprodutiva, impactam o tipo de integração e socialização nos espaços sociais em uma região de maioria branca.

É preciso considerar que a primeira leva de imigrantes haitianos não chegou ao oeste catarinense de forma espontânea, houve um movimento empreendido por empresários locais de ir buscá-los no Acre, em razão da falta de braços na região oeste catarinense. Os empresários arcaram com os custos da viagem do Acre para Chapecó e com subsídios para alojamento 
desses trabalhadores, como forma de estímulo para a permanência na cidade. Embora a maior concentração de trabalhadores estrangeiros esteja atualmente nas agroindústrias locais e na construção civil, uma volta pelos estabelecimentos comerciais do centro da cidade de Chapecó revela trabalhadores haitianos trabalhando em supermercados e padarias.

Sandra Bordignon (2016), em sua dissertação de mestrado sobre a inserção dos imigrantes haitianos nos contextos educativos escolares e não-escolares, caracterizou a presença haitiana no oeste catarinense por meio de três movimentos. O momento inaugural da presença haitiana na região oeste seria resultado da demanda das empresas frigoríficas e agroindústrias que patrocinaram a vinda dos primeiros haitianos para a região. Essa presença seria hegemonicamente masculina. O segundo movimento seria caracterizado pela vinda de mulheres haitianas e um terceiro movimento caracterizado pela vinda dos filhos dos imigrantes haitianos.

O fato de que a vinda de haitianos para a região oeste catarinense seja consequência da falta de braços para determinados tipos de trabalho não torna essa presença desejável. Em matéria divulgada no dia 02 de abril de 2015, um portal de notícias da cidade de Xaxim, vizinha à cidade de Chapecó, o Click Xaxim, destacou a preocupação da câmara de vereadores da cidade com a presença dos imigrantes haitianos, apontada quase em termos de uma invasão haitiana. A cidade de Xaxim tem aproximadamente vinte e sete mil habitantes. Um dos vereadores, mencionado na matéria, requereu um levantamento do número de haitianos na cidade, pois "teria ouvido falar" que um número de quatro ou cinco mil haitianos chegaria à cidade:

[...] o vereador questiona como serão prestados serviços de saúde, assistência médica, educação, alimentação, moradia, como o município irá se comprometer com essa gente [...] Agenor Junior Maier, vereador do (PP), disse que é preciso saber que parceria foi efetuada entre as empresas que trouxeram essas pessoas para trabalhar na região (Aurora e Rafitec), se eles chegaram com boas condições de saúde 
e as empresas se comprometeram em dar saúde, educação, moradia, alimentação aos haitianos [...] Já, o futuro dessas crianças preocupa o vereador Amarildo Maroco (PSD). Segundo ele, muitas grávidas haitianas estão circulando pela cidade, em outros casos, famílias inteiras estão vindo ao Brasil. Contudo, o que preocupa o vereador é como será dada assistência a essas pessoas, como será a adaptação desse povo e como será a aceitação dos brasileiros" (grifos nossos).

Apesar da vinda dos haitianos para o Brasil estar respaldada pela presença brasileira no Haiti, por meio da Missão das Nações Unidas para Estabilizar o Haiti (MINUSTAH) - que, após o terremoto de 2010, fez com que o Brasil fosse inserido na rota migratória haitiana (METZNER, 2014) - e em acordos para facilitar a entrada dos imigrantes haitianos no Brasil, os vereadores, mencionados na matéria, comportam-se como se o local, no caso a cidade de Xaxim, não estivesse subordinada às normativas nacionais, ao suporem que deveriam ser consultados sobre a vinda dos imigrantes haitianos.

As falas reproduzidas pelo informativo Click Xaxim são feitas de forma a transformar os haitianos em outros, estranhos, ameaçadores, indesejáveis e inaceitáveis. A resistência presente nas falas de vereadores também é reproduzida por pessoas comuns, que convivem com os trabalhadores haitianos no trabalho ou nos bairros, nas formas de sociabilidade cotidiana de uma forma ainda mais explícita, como demostram os dados coletados em um bairro de trabalhadores na cidade de Chapecó em 2015:

Eu acho que as vagas de trabalhos deveriam ser para os brasileiros, eles, estão deixando pessoas sem trabalho, não é racismo nada, as empresas estão mandando embora os brasileiros para segurar eles, estão em todos os setores. (Entrevistada Chica)

Acho que esse pessoal tem direito de ter trabalho, de uma condição de vida melhor, mas acho que o governo tem que se preocupar para não deixar trazer muita gente de fora, 
e deixando faltar às coisas para a nossa gente, eu penso assim, a gente precisa de saúde, de educação, de emprego. (Entrevistado Nico)

[...] Se pensar para nós (brasileiros) influencia a presença deles (estrangeiros), pois faltará para nós, o emprego, no posto de saúde. (Entrevistado Adão)

[...] chega, nós temos bastante problemas de desemprego, de saúde, e eles estão em todas as partes por aqui. (Entrevistada Chica)

Do ponto de vista dos estudos de imigração, o número de haitianos no Brasil e na região oeste é estatisticamente insignificante (PERAZABREEDY, 2014). Estima-se que a cidade de Chapecó abrigue em torno de 2.500 haitianos e que esse número seja de 55.000 para todo o Brasil. Contudo, do ponto de vista das relações sociais e intergrupais esse número é suficiente para revelar a qualidade dessas relações e os significados que as permeiam. Em uma região que constrói a sua imagem valorizando a origem europeia, esse número tem como efeito alterar as paisagens demográficas e inserir de forma radical, pelo contraste com os corpos brancos, a presença negra no espaço urbano, gerando nos moradores a sensação de que "eles estão em toda parte".

Embora os brasileiros que ocupam o oeste catarinense não sejam homogêneos em sua origem, em seus discursos sobre a presença haitiana eles se constituem em "um nós" e transformam o haitiano, negro e estrangeiro em um outro, em outsiders. Na estratégia de se atribuir um maior valor "ao nós”, recorrente nos grupos estabelecidos (ELIAS \& SCOTSON, 2000), a referência ao outro é sempre permeada por indicativos de desprezo: "essa gente" "essas pessoas" "esse povo", "eles". Na matéria em questão, os haitianos em nenhum momento são nominados por meio de sua origem e nacionalidade: o povo haitiano, os trabalhadores haitianos, os imigrantes haitianos, as pessoas oriundas do Haiti, mas sim por termos que os distanciam da comunidade local, em termos que estabelecem fronteiras. 
A recepção à presença haitiana no oeste catarinense - seja pelos políticos locais, seja pelos moradores - tem ecos no regime racializado de representação que cerca o estado de Santa Catarina e o oeste catarinense como território branco/europeu. Está ligada a um longo processo de estereotipagem racial (HALL, 2016) que atinge os indígenas da região, os caboclos e agora os haitianos. Todos esses grupos têm passando por um processo de racialização que os coloca como o "Outro" da história do oeste catarinense e nas relações de sociabilidade cotidiana na cidade. Embora haitianos tenham a sua identidade constituída por elementos históricos muito distintos daqueles que permeiam a constituição das identidades brasileiras, seus corpos são lidos por meio das categorias binárias e reducionistas repertoriadas na representação das diferenças raciais construídas a partir da escravidão dos africanos e descendentes no Brasil, da ideologia da mestiçagem, que ancora a identidade nacional brasileira, da suposta singularidade histórica do estado de Santa Catarina, como território europeu e do colono desbravador e trabalhador como ícone do oeste catarinense. Qual é o funcionamento do processo de estereotipagem? De acordo com Hall, a estereotipagem é uma prática de produção de significados que: "reduz, essencializa, naturaliza e fixa a diferença. Em segundo lugar, a estereotipagem implanta uma estratégia de 'cisão', que divide o normal e aceitável do anormal e do inaceitável, em seguida exclue [sic] ou expele tudo o que não cabe, o que é diferente" (HALL, 2016, p.191). É exatamente esse movimento que temos visto acontecer com os imigrantes haitianos no oeste catarinense, visível no depoimento do professor voluntário do curso de português para haitianos promovido pela então Associação de Haitianos de Chapecó, coletado por Sandra Bourdignon (2016):

Vi então a necessidade de não só ensinar a eles [haitianos] gramática e tantas outras coisas complicadas que nossa língua tem, mas também ensinar a eles se defenderem nas ruas de Chapecó. Se um dia alguém assistir minhas aulas verá que dou aula sobre xingamentos também, xingamentos que eles sofrem e precisam saber como se defender e entender 
o que o outro está dizendo a ele. Dentro dessa questão já ouvi inúmeras histórias de preconceito que precisei ser forte para não chorar na sala de aula e todas elas se passaram em Chapecó. $\mathrm{Na}$ minha cidade. Abordo em toda a aula nossas expressões do oeste de SC e do Brasil, exemplo como o nosso famoso: "Cremm" e um que eles gostam muito: Que massa! E quando sou questionado sobre o que ensino aos meus alunos, respondo que: Os ajudo a saber como viver em Chapecó, a Chapecó que é fácil pra mim por ser branco e brasileiro, mas totalmente diferente para eles (grifos nossos).

Fica evidente na fala do professor que os xingamentos dirigidos aos haitianos e haitianas nas ruas de Chapecó estão inscritos na representação racial da diferença (HALL, 2016), uma vez que ele coloca a sua condição de branco como algo que o protege e que facilita as suas vivências na cidade. E nesse sentido, desvela a partir desse lugar, com sua visão crítica, a branquitude como um lugar de poder (SCHUCMAN, 2013). São os corpos negros dos haitianos e haitianas o elemento provocador dos xingamentos e não o fato serem estrangeiros. Por serem negros, tornamse de imediato imigrantes indesejáveis na terra que construiu a sua história supervalorizando a presença imigrante. É essa relação de poder, com base nos significados atribuídos à raça, que faz com que sejam constantemente nominados como "eles". O fato de a história da região oeste catarinense ter sido construída por meio da ideia do vazio demográfico e do mito do desbravador, associado ao imigrante europeu, visto como aquele que trouxe o desenvolvimento local, tem como consequência a negação de qualquer traço da presença africana e de seus descendentes na região, bem como a invisibilidade das populações indígenas, cuja presença física pode ser percebida nas ruas da cidade. Um depoimento bastante citado pelos pesquisadores que têm se dedicado a desvelar a história regional do oeste catarinense (RENK, 2000, 2014; POLI, 2014; HASS, 2012) é do Wenceslau de Souza Breves. A narrativa de Breves é uma espécie de relato de viajante, fornece algumas impressões sobre o poder local e as formas de organização da cidade de Chapecó, no período de 1920 a 1924, quanto esteve na região como funcionário da Comissão Técnica Administradora 
de Terras, com o objetivo de demarcar as terras que estavam sendo concedidas às empresas colonizadoras. Breves era originário do estado do Rio de Janeiro e de uma família de proprietário de terras e escravocrata. Quanto à formação da população de Chapecó descreve o autor:

Em 1920 a população de Chapecó era praticamente cem por cento constituída por brasileiros da velha estirpe. Percebia-se em quase todos uma distante mistura de brancos com índios. Também em seu método de trabalho, em seus defeitos e qualidades se percebia a velha ascendência indígena. Quanto a pretos, eram raríssimos. (BREVES, 1985, p.19)

O brasileiro da velha estirpe nas categorias nativas do oeste catarinense é o brasileiro miscigenado, conhecido por "brasileiro" ou caboclo, cuja presença no território é anterior à chegada dos imigrantes alemães, italianos, poloneses e seus descendentes, que segundo Alcides Goulart Filho (2002) se dirigiram ao oeste catarinense entre 1917 e 1950 e fizeram parte das frentes pioneiras de colonização capitalista.

De acordo com Poli (2014), os caboclos podem ser considerados os primeiros desbravadores do oeste catarinense, embora não seja essa a representação dominante em torno da cidade. De certa forma teriam preparado o terreno para as empresas colonizadoras, responsáveis pela marcação de terras que foram vendidas aos imigrantes europeus e aos seus descendentes. O encontro desses grupos (brasileiros e europeus), permeado por diferentes interesses, implicou em disputa pela terra e pela forma de cultivá-la. Com a presença italiana e alemã na região, a "pureza" dos corpos brancos tornou-se um marcador de virtude e de distinção em favor daqueles que ficaram conhecidos regionalmente como colonos de origem (RENK, 2014): puros, pioneiros, desbravadores, corajosos, trabalhadores, capitalistas, modernos, europeus, sob a batuta dos quais, finalmente, teria ocorrido o desenvolvimento regional. Virtudes essas utilizadas como dispositivos de poder no processo de exclusão e marginalização dos povos indígenas e do caboclo, indígena miscigenado, transformado em negro, no contraste com o branco. O próprio relato de Breves, mencionado acima, está impregnado de juízos de valor que 
associam a população cabocla à pobreza e ao atraso e a população de colonos ao progresso e à prosperidade.

Do ponto de vista da constituição da cidadania os colonos de "origem" são brasileiros - uma vez que a maioria (descendentes) nasceu em solo brasileiro - têm direitos e deveres que tocam a todos os brasileiros e se utilizam dos serviços sociais enquanto brasileiros. Contudo, o monopólio dos recursos de poder pelos “de origem", referenciado nos corpos brancos e nos nomes de família, estabelece uma hierarquia violenta entre os grupos, que é estruturante das relações sociais e da forma como se distribui o poder, o prestígio e o status no oeste catarinense.

\section{O QUE A IMIGRAÇÃO HAITIANA TEM A DIZER SOBRE AS RELAÇÕES RACIAIS NO BRASIL?}

A região oeste catarinense é marcada pelo discurso da presença estrangeira associada ao projeto de ocupação territorial e desenvolvimento local. Não obstante esse histórico, a presença haitiana é percebida como uma ameaça, como vimos acima. As representações sobre os haitianos no imaginário local estão repletas de estigmas grupais raciais, que os transforma em outsiders (ELIAS \& SCOTSON, 2000) na relação com os moradores locais.

Em pesquisa sobre as formas de sociabilidade entre haitianos e a população local de Chapecó em um bairro próximo a uma agroindústria da cidade, era bastante comum o entrevistador, identificado como branco, se deparar com falas e discursos dos trabalhadores locais que os colocavam em uma posição de maior valor humano, justificada pela origem. É assim que o entrevistado abaixo explica o desenvolvimento do estado de Santa Catarina: "Os fatores sociais de índices bons do estado [Santa Catarina] tem relação com a imigração europeia, os traços o jeito do povo europeu, povo guerreiro, batalhador, isso vem ficando, uma herança genética que fica, e a gente carrega isso" (Entrevistado Nico).

Em seu livro Cultura e Representação, Stuart Hall (2016) evidencia a tendência dos brancos à naturalização da diferença, essa naturalização incidiria mais fortemente sobre a cultura negra, como uma forma 
de aprisionar os negros em um estado de natureza e de negar-lhes a possibilidade de mudança. No entanto, na fala acima, a fixidez das virtudes atribuídas ao grupo branco, também são explicadas pela natureza: "uma herança genética que fica". O que sugere que no universo do senso comum ainda é possível encontrar o que Frantz Fanon chamou de racismo vulgar: "o racismo vulgar, primitivo, simplista, pretendia encontrar no biológico a base material da doutrina" (FANON, 1980, p.36).

O atual fluxo migratório para a região oeste de Santa Catarina diferencia-se dos fluxos passados, não se trata de uma imigração incentivada pelo Estado com fins de "ocupação do território". Outra diferença é o caráter urbano das atividades laborais desenvolvidas pelos imigrantes haitianos, em contraposição ao destino em atividades agrícolas dos imigrantes ou descendentes que vieram do Rio Grande do Sul para o oeste catarinense, entre 1917 e 1950. E principalmente, pela marcação da diferença racial, da qual os brancos estão protegidos pelo poder que a branquitude lhes confere (SCHUCMAN, 2013).

A investigação das relações entre os moradores locais e imigrantes haitianos tem revelado aspectos da dinâmica sociocultural regional e nacional muitas vezes romantizada pela ideia de igualdade, cordialidade, hospitalidade e democracia racial que convencionou-se associar ao caráter brasileiro.

No contexto geral, não têm sido raros os casos de conflitos envolvendo brasileiros e haitianos, com características xenofóbicas e racistas. Além do mais, estamos no Brasil em um momento de intensificação das tensões raciais, em razão, do desmoronamento do mito da democracia racial, da implementação de políticas públicas específicas para a população negra e de um processo de identificação estética associado à negritude. Respaldados em Kabengele Munanga (2012), ressaltamos que a negritude, tendo sua origem na cor da pele negra, transcende o biológico, é uma de tomada de consciência, ligada à identidade, sobre o processo de desumanização ao qual foram submetidos os não-brancos, a partir do encontro com o Ocidente.

As tensões e conflitos entre brancos e negros no Brasil, outrora silenciados, em razão dos diferenciais de poder, começam a aparecer 
abertamente, em razão de uma retomada de valorização da identidade negra no Brasil e de uma ocupação mínima de espaços de poder por pessoas negras. Não apenas os imigrantes haitianos têm vivenciado situações que remetem ao regime racializado de representação brasileiro, como também têm ganhado visibilidade casos de racismo contra a população negra em geral, principalmente pelo efeito de compartilhamento possibilitado pelas redes sociais.

$\mathrm{Na}$ conjuntura atual é possível supor que nem a narrativa nacional da brasilidade mestiça nem a "narrativa das origens", presente no oeste catarinense, favoreça a integração haitiana no contexto brasileiro. Afirmação que aponta para a necessidade de pesquisas comparativas sobre os elementos que permeiam as relações entre brasileiros e haitianos em diferentes regiões do Brasil. Nas entrevistas e conversas informais com os haitianos e haitianas, percebe-se que eles têm vivenciado um choque de representações. Desde o Haiti havia uma expectativa dos haitianos de que o Brasil seria um país de acolhimento em razão de uma história compartilhada com o Haiti a partir da experiência da colonização e da escravidão e pelo fato de identificarem o Brasil como um país de população negra. Contudo, o processo de colonização no Haiti e no Brasil tiveram desdobramentos muito diferentes. A assimilação da cultura africana à cultura popular brasileira, por exemplo, como elemento de brasilidade se deu subordinada à matriz europeia e ao poder simbólico do branco. Foram os brancos que definiram o lugar da cultura africana no Brasil, inclusive descaracterizando-a enquanto cultura africana. No Haiti, embora também haja uma disputa entre os elementos de origem africana e a presença europeia, marcadamente francesa, a ruptura com o sistema colonial por meio de uma luta revolucionária possibilitou uma ligação mais direta entre a cultura haitiana e a cultura africana, expressa seja na prática religiosa do vodu, seja no uso do creole como língua (HANDERSON, 2010).

Nessas conversas e entrevistas com haitianos e haitianas temos descoberto que o povo haitiano estabelece com Brasil, desde o Haiti, uma relação emocional, de torcedores, em razão do impacto do futebol na representação haitiana sobre o Brasil. A ideia que o haitiano tem do Brasil, antes de sair do Haiti, é mediada pela imagem vendida pelo futebol 
brasileiro, pela concepção de que o Brasil é um país em desenvolvimento e pela alegria associada às festas, em especial ao carnaval. No contraponto desse imaginário, são recebidos no Brasil como pessoas indesejáveis e sofrem hostilidades diárias em seu cotidiano. Em março de 2017, o NEABI (Núcleo de estudos afro-brasileiros e indígenas) da UFFS, campus Chapecó, produziu e divulgou um vídeo com o depoimento de uma estudante haitiana, falando de suas experiências com a cidade, revelando o contato inesperado com o racismo e, acima de tudo, a sua racialização enquanto mulher negra. O vídeo foi veiculado pelo canal Youtube e desde então atingiu 7.953 visualizações e 353 comentários. Parte significativa dos comentários é no sentido de dizer que a estudante haitiana é uma equivocada e que deveria voltar para o Haiti. Embora o vídeo seja de março de 2017, ele continua recebendo comentários. Um dos comentários mais recentes revela elementos de estereotipagem racial (HALL, 2016), ao contrapor as virtudes do povo do sul aos vícios e fraqueza moral dos haitianos:

Vai pro Rio de Janeiro ou pra Bahia se não tá gostando daqui. Além de mamar nas tetas dos governos sulistas e tirar da boca do povo do Sul, ainda tem coragem de reclamar. Viva o povo trabalhador do Sul. Imigrantes alemães, italianos, poloneses, portugueses e espanhóis que construíram esse lugar a partir do suor do seu trabalho, hoje ter que ver gente que vem lá da pqp, não trabalham e nada fazem pra contribuir com o crescimento e prosperidade do local, ainda reclamarem de barriga cheia. Lamentável! ${ }^{5}$

As experiências iniciais do grupo estrangeiro são permeadas pela incompreensão. Um haitiano relata que "aqui no bairro ninguém ajuda ninguém, a gente não conversa com os brasileiros, parece que eles têm medo da gente" (Entrevistado Sérgio). Outro "não sei por que no trabalho

\footnotetext{
${ }^{5}$ Ver comentários em NEABI-UFFS-CH. Vídeo Ser imigrante e negra no Sul do Brasil. Disponível em: https://www.youtube.com/watch?v=3bDrSEZgtvw\&t=14s Acesso em: $1 / 02 / 2018$.
} 
tem pessoas ruins que ficam dizendo coisa para a gente que é de fora" (Entrevistado Pablo).

Como o país do racismo cordial pode ser experimentando como um lugar de racismo intenso? $\mathrm{O}$ racismo intenso experimentado pelos haitianos na região oeste se revela na aversão ao contato com os novos imigrantes, uma das características da exclusão imposta aos outsiders pelo grupo estabelecido e nos discursos de desprezo. Nas representações da população, os haitianos não são limpos, são portadores de doença, são mortos de fome, preguiçosos, perdulários, e os homens são vistos como uma ameaça às mulheres.

Nas relações de sociabilidade cotidiana os moradores locais evitam sentar ao lado de pessoas haitianas (por exemplo no transporte público) ou evitam frequentar os mesmos espaços públicos. Outro aspecto observado pelo trabalho de campo é a ausência de interação entre os dois grupos fora de espaços onde ela ocorre de forma obrigatória: escolas e locais de trabalho. "o povo [do bairro] gosta de olhar, há quem diga, eles [haitianos] vão trazer doenças, mas acho que é só um pouco de disfarce para não se misturarem" (Entrevistada Maria). Uma outra entrevistada revela mecanismos para evitar o contato: "No bairro, eles ficam com o celular na rua, vivem na esquina, ali tem o ginásio e a academia, minhas meninas iam lá e das vizinhas fazer academia, não dá para deixar, eles ficam lá, acho que eles não são acostumados a ficar dentro de casa, parece”. (Entrevistada Chica).

A cidade, bem como o bairro, tem uma população que se autodenomina "desbravadora e trabalhadora" e que compreende a cidade como um lugar de trabalho e privilégio, associada às virtudes da presença europeia. Em contraposição à imagem positiva que essa população produz de si, a cor dos trabalhadores haitianos é utilizada como um mecanismo de rebaixamento social, assim como o suposto vínculo à pobreza. Um senhor do grupo estabelecido, faz referência explicita a cor: "a diferença entre brasileiro e estrangeiro, no começo deu um baque [impacto, estranhamento] aquele negócio da cor deles, os brasileiros não aceitam bem, é estranho". Segundo os relatos, é comum os vizinhos brasileiros se referirem aos vizinhos haitianos como "essa pretaiada". 
Outro importante aspecto a ser considerado é a tentativa por parte dos moradores locais de subtrair dos haitianos as virtudes relacionadas ao trabalho, tão valorizadas no contexto da imigração europeia. Os haitianos vieram para Chapecó para trabalharem em lugares muitas vezes não desejados pelos trabalhadores locais e em trabalhos pesados. Alguns, entre esses trabalhadores, chegam a ter dois empregos. No entanto, no regime racializado de representação a associação ao trabalho como virtude lhes é negada. Uma trabalhadora de uma das agroindústrias da região avalia que: "eles são preguiçosos, não querem nada com nada, eles sentam nas cadeiras aquelas que abrem pra trás, ou deitam nas cadeiras, e chegam a roncar, querem vida boa, por que lá (país de origem) sofriam como cachorros, passavam fome" (Entrevistada Chica).

Esse é outro estigma bastante presente nas representações dos moradores locais em relação aos haitianos: a pobreza. Embora as entrevistas realizadas no trabalho de campo tenham sido feitas em um bairro de trabalhadores, cuja maioria da população exerce os mesmos tipos de trabalho que os haitianos na agroindústria, em suas representações a pobreza está associada aos haitianos. Nesse sentido, há uma expectativa desses moradores do bairro de que o comportamento e o consumo dos haitianos correspondam à imagem de pobreza por eles construída. Quando isso não acontece, a pobreza é associada a uma postura irresponsável e perdulária em relação ao dinheiro: "eu não entendo, quero que você veja por aí, e veja se um dos nossos tem um celular que nem os deles" (Entrevistado Adão). Não é por acaso que o morador diga que não entende, pois há uma inadequação entre a representação que ele tem de si, como parte de um grupo de maior valor, e do grupo outsider como pobre, morto de fome e o fato de serem os haitianos portadores de aparelhos com melhor tecnologia que os moradores brasileiros do bairro. O que implica em mais uma forma de julgamento moral "se eles economizassem, eles não teriam que imigrar" (Entrevistado Adão).

Quais os usos os moradores locais, trabalhadores ou de origem trabalhadora têm feito de sua branquitude? Esse é um aspecto que os estudos sobre a branquidade (VON WARE, 2004) têm explorado. Segundo Roediger, os marxistas, que têm uma longa tradição nos estudos sobre 
a classe trabalhadora, ignoraram o lugar e papel da raça na constituição da identidade de classe: "o mais grave talvez seja a tendência contínua a romancear os membros da classe trabalhadora branca, não levantando o problema de porque eles passaram a se considerar brancos, e com que resultados" (ROEDIGER, 2004, p.53). Citando Du Bois, Roediger lembra que os trabalhadores brancos ao adotarem ideias racistas passam a pensar a si mesmo como brancos e a defenderem os seus interesses como brancos.

Os estigmas direcionados aos haitianos são os mesmos direcionados à população negra brasileira, com o agravamento de virem de um país em situação precária do ponto de vista do desenvolvimento econômico e de não dominarem a representação racial hegemônica.

Mesmo sem conhecer a história do Haiti - não é raro os moradores do oeste catarinense acharem que os haitianos são africanos - cria-se um imaginário sobre os haitianos como uma "população de coitados". A pergunta que Elias e Scotson (2000) nos provocam a responder é como diferenciais de poder são traduzidos em diferenciais de valor humano nas relações intergrupais? Os brasileiros são os trabalhadores mais antigo no bairro, em comparação aos haitianos, o que lhes garante inclusive alguns diferenciais econômicos. Muitos são proprietários de suas casas e contam com mais uma casa em seu terreno para aluguel, o que é revertido em vantagem econômicas por significar uma renda extra e a prerrogativa de decidirem para quem alugar esses imóveis. Essa situação fixa uma relação de poder entre trabalhadores brasileiros ou brasileiros que têm sua origem como trabalhadores e os trabalhadores haitianos. Outro recurso de poder dos trabalhadores brasileiros sobre os haitianos é o fato de dominarem a língua e os códigos locais e acima de tudo os valores associados aos corpos brancos.

Se a narrativa oficial do Brasil mestiço camuflava revelações tão explícitas à raça na afirmação de poder do grupo branco em relação aos Outros, no oeste catarinense, onde essa presença negra é minoritária e onde a origem é sempre reivindicada, a branquitude é acionada de forma muito espontânea. O que para um observador desavisado pode parecer uma reação à presença estrangeira, é, no final, uma reação à presença negra na suposta terra dos brancos. É como brancos que os moradores 
locais constroem os seus discursos sobre os imigrantes haitianos. Ao se conceberem como um "nós" traçam uma fronteira entre locais e estrangeiros que não é apenas delimitada pela nacionalidade, mas também pela forma como os corpos haitianos são racialmente significados. Os estrangeiros haitianos, o "eles" do discurso dominante, são acima de tudo concebidos pelo prisma da ameaça: ameaça aos empregos, às filhas, à saúde, e por fim, à branquitude. Muitos dos elementos presentes no discurso dos moradores locais implicam no desejo de manter os outsiders distantes, uma vez que o encontro dos corpos, dos corpos negros com os corpos brancos, poderia desfigurar aquilo que é tão caro a essas pessoas, a convicção da pureza de suas origens. O "povo do bairro tem medo de perder status, e principalmente, de haver atrito de cor e raça, tem medo com uma nova convivência, mistura, o povo do Sul não é de mistura" (Entrevistada Maria). Do medo resulta o desejo do controle, da diminuição da presença que ameaça: "o governo deve controlar, para não aumentar muita a população, porque aumentando a população [haitiana] com certeza vai começar a dar problema social, vai misturar raça, vai modificar costumes, vai alterar o jeito de nosso estado, país" (Entrevistado Nico). É explícita, nessa fala, a ideia do controle como forma de evitar o contato entre os dois grupos e de que a mistura traria prejuízos para os costumes e para o grupo considerado superior, assim como defendiam as teorias racialistas do século XIX.

A categorização feita por Oracy Nogueira sobre as relações raciais no Brasil pode nos dar algumas pistas para a compreensão das relações de poder entre brancos e não-brancos no oeste catarinense. Nogueira batizou de preconceito de marca a política racial brasileira em contraposição à forma como essas relações se estruturariam na configuração norte-americana, denominada por ele como preconceito de origem: "o preconceito de marca determina uma preterição, o de origem, uma exclusão incondicional dos membros do grupo atingido, em relação a situações ou recursos pelos quais venham a competir com os membros do grupo discriminador" (NOGUEIRA, 2006, p.293).

Nessa acepção, o preconceito de marca se manifestaria por meio dos significados atribuídos ao fenótipo dos indivíduos, enquanto o preconceito 
de origem se processaria por meio da leitura da ascendência. Onde predomina o preconceito de marca, alguns indivíduos com ascendência africana podem furar o bloqueio racial e se inserir no meio do grupo racial hegemônico, branco, sem que as relações de poder intergrupais sejam alteradas. Como o Brasil tem como fundamento ideológico de sua política racial a mestiçagem, os limites e as restrições à população negra estão condicionados às classificações fenotípicas, que, quando associadas a outros elementos, podem alterar o status do indivíduo negro (preto e pardo), mas não o do grupo.

A valorização da suposta particularidade do processo de ocupação da região oeste de Santa Catarina faz com que o discurso sobre a raça seja utilizado em oposição à mistura e à miscigenação. Na região oeste de Santa Catarina os grupos demográficos que compõem o cenário local são identificados por suas diferentes origens e há uma hierarquização entre eles que repõe o lugar da raça de forma explicita, mesmo que em vários momentos encoberta pela noção de etnia. Nesse aspecto é possível dizer que mais do que o preconceito de marca, na região oeste predomina o preconceito de origem. O contato com os não brancos é sentido como uma ameaça, o desejo de distanciamento é espontaneamente explicitado, o que evidencia que os brancos estão investidos de recursos para proteger os seus privilégios enquanto grupo hegemônico e um desses recursos é a forma como representam os imigrantes haitianos.

As percepções que os moradores locais produzem sobre si, enquanto parte de um grupo de maior valor humano e dos haitianos como outsiders evidenciam a relevância social da categoria raça não só para pensar as formas de subordinação dos não-brancos, mas também para pensar como os brancos se significam e se auto percebem no processo de interdependência entre locais e estrangeiros. 


\section{REFERÊNCIAS BIBLIOGRÁFICAS}

BENTO, Maria Aparecida. Branqueamento e Branquidade no Brasil In: CARONE, Iray; BENTO, Maria Aparecida. Psicologia Social do Racismo: estudos sobre branquitude e branqueamento no Brasil. Petrópolis: Vozes, 2014.

BORDIGNON, Sandra. Inserção dos imigrantes haitianos nos contextos educativos escolares e não escolares. Chapecó, 2016. Dissertação (Mestrado em Educação) - Universidade Comunitária da Região de Chapecó.

BREVES, Wenceslau de Souza. O Chapecó que eu conheci. Revista do Instituto Histórico e Geográfico de Santa Catarina. Florianópolis: ano 3, n. 06, p.07-73, 1985.

CARDOSO, Paulino de Jesus Francisco. Em busca de um fantasma: as populações de origem africana em Desterro, Florianópolis, de 1860 a 1888. Padê: estudos em filosofia, raça, gênero e direitos humanos. UniCEUB, FACJS, Brasília, v.2 n.1, 2007.

CLICK XAXIM. Vereadores de Xaxim se preocupam com a grande quantidade de Haitianos no município. Portal Click Xaxim, Xaxim, 02 abr. 2015. Disponível em < http://www.clickxaxim.com.br/ noticias/1384-vereadores-de-xaxim-se-preocupam-com-a-grandequantidade-de-haitianos-no-municipio> Acesso em: 05/05/2016.

CONSELHO NACIONAL DE IMIGRAÇÃO - CNIg. Resolução normativa $\mathrm{N}^{\circ}$ 97, de 12 de janeiro de 2012.

ELIAS, Norbert. O processo civilizador. Uma história dos costumes. Rio de Janeiro: Zahar, v.1, 1994.

ELIAS, Norbert;SCOTSON, John. L. Osestabelecidos e os Outsiders. Sociologia das relações de poder a partir de uma pequena comunidade. Rio de Janeiro: Zahar 2000.

FANON, Frantz. Racismo e Cultura. In: FANON, Frantz. Em defesa da revolução africana. Lisboa: Livraria Sá da Costa, 1980, p.35-48. 
FERNANDES, Duval; CASTRO, Maria da Consolação Gomes. A migração haitiana para o Brasil: Resultado da pesquisa no destino. In: La Migración Haitiana Hacia Brasil. OIM, Cuadernos Migratorios n. 6, p. $51-66,2014$

FREYRE, Gilberto. Casa Grande e Senzala: a formação da família brasileira sob o regime da economia patriarcal. Rio de Janeiro: Record, 1995.

GOULART FILHO, Alcides. A formação econômica de Santa Catarina. Ensaios FEE, Porto Alegre, v.23, n.2, p.977-1007, 2002.

G1 SC. Aos 97 anos, Chapecó se destaca por ofertas de emprego e crescimento. G1 Santa Catarina, Santa Catarina, 25, 2014. Disponível em: <http://g1.globo.com/sc/santa-catarina/noticia/2014/08/aos97-anos-chapeco-se-destaca-por-ofertas-de-emprego-e-crescimento. html>. Acesso em: 13/02/2016.

HALL, Stuart. Cultura e representação. Rio de Janeiro: Editora PUC-Rio: Apicuri, 2016.

HANDERSON, Joseph. Vodu no Haiti, Candomblé no Brasil: identidades culturais e sistemas religiosos como concepções de mundo AfroLatino-Americano. Pelotas, 2010. Dissertação (Mestrado em Ciências Sociais) - Instituto de Sociologia e Política, Universidade Federal de Pelotas.

HASS, Monica. O Linchamento que muitos querem esquecer. Argos: Chapeco, 2012.

KOIFMAN, Fábio. Imigrante ideal: O Ministério da Justiça e a entrada de estrangeiros no Brasil (1941-1945). Rio de Janeiro: Editora José Olympio (Edição para Kindle), 2012.

LEITE, Ilka B. Descendentes de africanos em Santa Catarina: invisibilidade e segregação In: LEITE, Ilka. B. (Org.). Negros no Sul do Brasil: invisibilidade e territorialidade. Florianópolis: Letras Contemporâneas, 1996. 
MAGALHÃES, Luís Felipe Aires. A imigração haitiana em Santa Catarina: perfil sociodemográfico do fluxo, contradições da inserção laboral e dependência de remessas no Haiti. Campinas, 2017. Tese (Doutorado em Demografia) - Instituto de Filosofia e Ciências Humanas, Universidade Estadual de Campinas.

MAGALHÃES, Luís Felipe Aires; BAENINGER, Rosana. Imigração haitiana no Estado de Santa Catarina: Fases do fluxo e contradições da inserção laboral. Blucher Social Sciences Proceedings, São Paulo, v.2, n. 2,2016

MAMIGONIAN, Beatriz Gallotti. Africanos em Santa Catarina: escravidão e identidade étnica (1750-1850). In: Seminário Internacional "Nas Rotas do Império: Eixos Mercantis, Tráfico de Escravos, Relações Sociais no Mundo Português". Universidade Federal do Rio de Janeiro, junho, 2006.

METZNER, Tobias. La migración haitiana hacia Brasil: estudio en el país de origen. In: Cuadernos Migratorios, $n^{\circ} 6$ "La migración haitiana hacia Brasil: características, oportunidades y desafíos”. Buenos Aires: OIM, 2014. p.15-32.

MUNANGA, Kabengele. Negritude: usos e sentidos. Belo Horizonte: Autêntica Editora, 2012.

NEABI-UFFS-CH. Vídeo Ser imigrante e negra no Sul do Brasil. Disponível

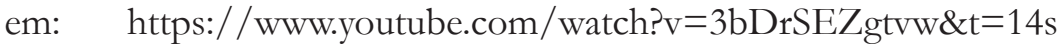
Acesso em: 1/02/2018

NOGUEIRA, Oracy. Preconceito racial de marca e preconceito racial de origem: sugestão de um quadro de referência para a interpretação do material sobre relações raciais no Brasil. Tempo Social, Revista de Sociologia da USP, v. 19, n. 1, 2006.

ORTIZ, Renato. Cultura brasileira e identidade nacional. São Paulo: Brasiliense, 1985.

PERAZA-BREEDY, Jorge. Introducción. In: Cuadernos Migratorios, n6 "La migración haitiana hacia Brasil: características, oportunidades y desafíos”. Buenos Aires: OIM, 2014. p.11-14. 
POLI, Jaci. Caboclo: pioneirismo e marginalização. Cadernos do CEOM, Chapecó, ano 19, n.23, 2014.

RENK, Arlene. A colonização do oeste catarinense: as representações dos brasileiros. Cadernos do CEOM, Chapecó, ano 19, n.23, 2014.

RENK, Arlene. Uns trabalham outros lutam: brasileiros e a luta na erva. Horizontes Antropológicos, Porto Alegre, ano 6, n. 14, 2000.

ROEDIGER, David. Sobre autobiografia e teoria: uma introdução. In: WARE, Vron (org.). Branquidade: identidade branca e multiculturalismo. Rio de Janeiro: Editora Garamond, 2004.

SCHUCMAN, Lia Vainer. Entre o encardido, o branco e o branquíssimo. São Paulo: Annablume: 2013.

SCHWARCZ, Lilia. Complexo de Zé Carioca: notas sobre a identidade mestiça e malandra. Revista Brasileira de Ciências Sociais, São Paulo, n. 29, p. 49-63, 1995.

UNIVERSIDADE FEDERARAL DA FRONTEIRA SUL. Resolução n.32/2013. Institui o Programa de Acesso à Educação Superior da UFFS para estudantes haitianos - PROHAITI e dispõe sobre os procedimentos para operacionalização das atividades do programa. Chapeco, 12 de dezembro de 2013.

WARE, Vron (org.). Branquidade: identidade branca e multiculturalismo. Rio de Janeiro: Editora Garamond, 2004. 
